\title{
ACUMULAÇÃO DE SILÍCIO EM ARROZ EM DIFERENTES CONDIÇÕES DE pH DA RIZOSFERA ${ }^{(1)}$
}

\author{
Lilian Aparecida de Oliveira ${ }^{(2)}$, Gaspar Henrique Korndörfer ${ }^{(3)}$ \& \\ Ana Cristina Pereira ${ }^{(4)}$
}

\begin{abstract}
RESUMO
A quantidade de Si acumulada pelas plantas depende do teor de Si disponível, e este, do pH do solo. É possível que a absorção e acumulação de Si em gramíneas possam estar associadas ao $\mathrm{pH}$ rizosférico. Este trabalho teve como objetivo estudar o efeito do pH de rizosfera na disponibilidade do Si no solo, na acumulação por plantas de arroz de sequeiro (vr. Epagri 109) e na produção de massa seca. Para isso, instalou-se um ensaio em casa de vegetação, em parcela subdividida, no esquema fatorial $5 \times 2$. Os cinco tratamentos (TR) foram constituídos de dose única de $\mathrm{N}\left(200 \mathrm{mg} \mathrm{kg}^{-1}\right)$, aplicada nas seguintes relações de $\mathrm{N}_{-} \mathrm{NH}_{4}{ }^{+} \mathrm{e}-\mathrm{N}_{3}{ }_{3}^{-}$: TR1 $=0,0: 1,0 ;$ TR2 $=0,25: 0,75 ;$ TR3 $=0,50: 0,50 ;$ TR4 $=0,75: 0,25 ; \mathrm{e}$ TR5 $=1,0: 0,0$. O fator subparcela consistiu da aplicação de $200 \mathrm{mg} \mathrm{kg}^{-1}$ de Si. As fontes de $\mathrm{N}$ usadas foram nitrato de cálcio e sulfato de amônio, e a fonte de $\mathrm{Si}$ foi o tetracloreto de $\mathrm{Si}$, aplicadas em uma amostra de Neossolo Quartzarênico. Para inibir a nitrificação foram utilizados $10 \mathrm{mg} \mathrm{kg}^{-1}$ de nitrapirina nos tratamentos em que amônio foi empregado. Os valores de $\mathrm{pH}$ rizosférico decresceram proporcionalmente ao aumento da concentração de $\mathrm{N}-\mathrm{NH}_{4}{ }^{+} \mathrm{e}$ influenciaram de forma significativa o teor de Si no solo: quanto maior o $\mathrm{pH}$ rizosférico, maior a disponibilidade de $\mathrm{Si}$ e maior a absorção pela planta de arroz.
\end{abstract}

Termos de indexação: Oriza sativa, nitrato, amônio.

\footnotetext{
(1) Parte da Tese de Mestrado do primeiro autor. Universidade Federal de Uberlândia - UFU. Recebido para publicação em abril de 2005 e aprovado em março de 2007.

${ }^{(2)}$ Mestre em Agronomia, Universidade Federal de Uberlândia - UFU. Caixa Postal 593, CEP 38400-902 Uberlândia (MG). E-mail: oliveiralilian152@hotmail.com

${ }^{(3)}$ Professor Titular do Instituto de Ciências Agrárias, UFU. Bolsista CNPq. E-mail: ghk53@terra.com.br

(4) Mestranda em Agronomia, Área de Concentração Solos, UFU. E-mail: pereiraana_2@hotmail.com
} 


\title{
SUMMARY: SILICON ACCUMULATION IN RICE IN DIFFERENT RHIZOSPHERE PH CONDITIONS
}

\begin{abstract}
The amount of silicon accumulated by plants depends on the concentration of available silicon, and this of the soil $\mathrm{pH}$. Silicon absorption and accumulation in grasses is possibly associated with the rhizosphere $\mathrm{pH}$. This study evaluated the effect of rhizosphere $\mathrm{pH}$ on $\mathrm{Si}$ absorption and accumulation in upland rice (Epagri $109 \mathrm{vr}$.). The experiment was carried out in a greenhouse in a $5 \times 2$ factorial design. The five treatments (TR) consisted of a single $\mathrm{N}$ dose $\left(200 \mathrm{mg} \mathrm{kg}^{-1}\right)$ applied in the following $\mathrm{N}-\mathrm{NH}_{4}^{+} / \mathrm{N}-\mathrm{NO}_{3}^{-}$proportions: TR1 = 0.0:1.0; TR2 $=0.25: 0.75 ;$ TR3 $=0.50: 0.50 ; T R 4=0.75: 0.25 ;$ TR5 = 1.0:0.0. The subplots were fertilized with $200 \mathrm{mg} \mathrm{kg}^{-1} \mathrm{Si}$. Calcium nitrate and ammonium sulfate were used as $N$ sources (with nitrification inhibitor) and silicon tetrachloride as Si source, applied to an Ustoxic Quartzipsamment. The $p H$ in the rhizosphere decreased with the increasing $\mathrm{N}-\mathrm{NH}_{4}{ }^{+}$concentration. The rhizosphere $\mathrm{pH}$ values influenced the Si concentration in the soil significantly: the higher the $\mathrm{pH}$, the greater the $\mathrm{Si}$ availability. The Si concentration in the aboveground plant parts varied according to soil Si.
\end{abstract}

Index terms: Oriza sativa, nitrate, ammonium.

\section{INTRODUÇÃO}

Uma característica das gramíneas é a capacidade de aumentarem o $\mathrm{pH}$ da rizosfera quando submetidas a nutrição com o $\mathrm{N}$ apenas na forma $\mathrm{NO}_{3}{ }^{-}$, pelo consumo de $\mathrm{H}^{+}$e conseqüente formação de $\mathrm{OH}^{-}$, e decrescerem o $\mathrm{pH}$ de rizosfera quando o suprimento de $\mathrm{N}$ na forma de $\mathrm{NH}_{4}{ }^{+}$(Marschner \& Romheld, 1983; Gijsman, 1990).

Entre as gramíneas, o arroz possui grande capacidade de absorção de Si pelas suas raízes, o qual é translocado, acompanhando o fluxo de transpiração, acumulando-se na parte aérea. O Si é absorvido de forma ativa por proteínas de membrana sintetizadas a partir de gene específico (Ma \& Takahashi, 2002); assim, a absorção e o transporte de Si na planta de arroz podem ocorrer durante toda a vida da planta, uma vez que não obedece a um gradiente de concentração.

O Si disponível no solo pode ser absorvido pelas plantas de arroz, como molécula não dissociada $\left(\mathrm{H}_{4} \mathrm{SiO}_{4}\right.$ - ácido silícico) e formas iônicas (Ma et al., 2001). A forma química do Si disponível depende do
pH do solo; quanto mais alcalino, maior o grau de ionização do $\mathrm{H}_{4} \mathrm{SiO}_{4}$ (Iler, 1979). Este trabalho teve como objetivo estudar o efeito do $\mathrm{pH}$ da rizosfera na disponibilidade do Si no solo, na acumulação por plantas de arroz e na produção de matéria seca.

\section{MATERIAL E MÉTODOS}

O experimento foi realizado em casa de vegetação. Utilizou-se amostra de um Neossolo Quartzarênico típico (AQ), sob campo natural, coletado no município de Santa Vitória - MG, em outubro de 2002, na camada de 0 a $20 \mathrm{~cm}$ (Quadro 1).

$\mathrm{O}$ experimento foi montado em vasos com $2 \mathrm{~kg}$ de solo, em delineamento inteiramente casualizado com parcelas subdivididas, sendo as parcelas os tratamentos com as diferentes relações de $\mathrm{N}_{-} \mathrm{NH}_{4}{ }^{+} \mathrm{e}$ $\mathrm{N}-\mathrm{NO}_{3}^{-}$(Quadro 2) e as subparcelas a aplicação de $200 \mathrm{mg} \mathrm{kg}^{-1}$ de $\mathrm{Si}$, obtendo-se, assim, um arranjo em esquema fatorial $5 \times 2$ com três repetições. Compararam-se as médias pelo teste de Tukey a $5 \%$.

\section{Quadro 1. Caracterização química e granulométrica de Neossolo Quartzarênico Típico (AQ)}

\begin{tabular}{|c|c|c|c|c|c|c|c|c|c|c|c|c|}
\hline $\mathrm{pH}\left(\mathrm{CaCl}_{2}\right)$ & MO & $\mathbf{P}$ & $\mathbf{K}$ & $\mathbf{S i}$ & $\mathrm{Ca}^{2+}$ & $\mathrm{Mg}^{2+}$ & $\mathrm{Al}^{3+}$ & Argila & Silte & $\begin{array}{c}\text { Areia } \\
\text { grossa }\end{array}$ & $\begin{array}{c}\text { Areia } \\
\text { fina }\end{array}$ & $\begin{array}{r}\text { Areia } \\
\text { total }\end{array}$ \\
\hline & $\mathrm{g} \mathrm{dm}^{-3}$ & $\ldots$ & $g \mathrm{dm}^{-3}$ & - & $-\mathrm{cr}$ & $\mathrm{mol}_{\mathrm{c}} \mathrm{dm}$ & -3 & 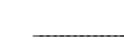 & 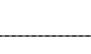 & $\%$ & 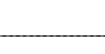 & \\
\hline 6,0 & 14 & 145 & 174 & 1,3 & 2,9 & 0,8 & 0,0 & 15 & 1 & 62 & 22 & 84 \\
\hline
\end{tabular}


Quadro 2. Relações de $\mathrm{N}-\mathrm{NH}_{4}^{+}$e N-NO${ }_{3}^{-}$utilizadas

\begin{tabular}{|c|c|c|c|}
\hline Tratamento & Relações $\left(\mathrm{N}-\mathrm{NH}_{4}{ }^{+}\right.$e $\left.\mathrm{N}-\mathrm{NO}_{3}^{-}\right)$ & $\mathrm{Ca}\left(\mathrm{NO}_{3}\right)_{2}$ & $\left(\mathrm{NH}_{4}\right)_{2} \mathrm{SO}_{4}$ \\
\hline & & \multicolumn{2}{|c|}{$\mathrm{g} \mathrm{kg}^{-1} \mathrm{de}$ solo } \\
\hline TR1 & $0,0: \quad 1,0$ & 1,7 & 0,0 \\
\hline TR2 & $0,25: 0,75$ & 1,2 & 0,3 \\
\hline TR3 & $0,50: 0,50$ & 0,9 & 0,5 \\
\hline TR4 & $0,75: 0,25$ & 0,5 & 0,8 \\
\hline TR5 & $0,1: 0,0$ & 0,0 & 1,0 \\
\hline
\end{tabular}

A espécie utilizada foi o arroz (Oriza sativa L.), variedade Epagri 109, com seis plantas por vaso. Durante a condução do ensaio, principalmente nas fases iniciais de cultivo, o solo foi mantido a $80 \%$ de sua capacidade de campo.

Com duas semanas de cultivo, foram aplicados $200 \mathrm{mg} \mathrm{kg}^{-1}$ de $\mathrm{N}$, com diferentes relações de amônio e nitrato (Quadro 2). A fonte de $\mathrm{N}_{-} \mathrm{NO}_{3}{ }^{-}$utilizada foi o $\mathrm{Ca}\left(\mathrm{NO}_{3}\right)_{2}$, e a de N-NH${ }_{4}^{+}$, o $\left(\mathrm{NH}_{4}\right)_{2} \mathrm{SO}_{4}$. Considerando que as amostras de solo foram previamente incubadas com $\mathrm{CaCO}_{3}, \mathrm{~K}_{2} \mathrm{SO}_{4}$ e $\mathrm{Ca}\left(\mathrm{HPO}_{4}\right)_{2}$, o balanceamento das bases não foi necessário, tendo em vista a análise química da amostra de solo utilizada para plantio.

Nos tratamentos em que se utilizou $\mathrm{N}-\mathrm{NH}_{4}{ }^{+}$foram aplicados $10 \mathrm{mg} \mathrm{kg}^{-1}$ do princípio ativo (nitrapirina) do inibidor de nitrificação "N-serve". A nitrapirina controla o processo de nitrificação por meio do controle da ação das Nitrobacter (Chancy \& Kamprath, 1982), preservando assim a forma amoniacal.

Além da adubação nitrogenada, foi feita também adubação silicatada, utilizando como fonte a soluçãopadrão de $\mathrm{Si} 1.000 \mathrm{mg} \mathrm{L}^{-1}$ de $\mathrm{Si}\left(\mathrm{SiCl}_{4}\right.$ em NaOH $14 \%$ ) Tritisol ${ }^{\circledR}$ Merck, aplicando-se $200 \mathrm{mg} \mathrm{kg}^{-1}$ de Si no solo.

Após 30 dias de crescimento das plantas, o solo dos vasos foi dividido em solo rizosférico (aderido às raízes) e não-rizosférico (solo do vaso que não entrava em contato direto com as raízes). A análise das concentrações de $\mathrm{N}-\mathrm{NO}_{3}{ }^{-}$e $\mathrm{N}-\mathrm{NH}_{4}{ }^{+}$no solo foi feita pelo processo de destilação. Foi ainda determinado o Si, seguindo o método descrito por Korndörfer et al. (2004), e medido o pH dos solos rizosférico e nãorizosférico em $\mathrm{CaCl}_{2}$ (Embrapa, 1979).

Nas plantas, determinou-se Si na parte aérea (caule + folha) e nas raízes, segundo metodo descrito por Korndörfer et al. (2004). A matéria seca e a concentração de clorofila também foram determinadas. Na leitura da concentração de clorofila foi utilizado microprocessador para calcular os valores SPAD ("Soil Plant Analysis Development”). O medidor portátil de clorofila permite medições instantâneas da intensidade da coloração verde, a qual tem relação direta com os teores de clorofila na planta (Argenta et al., 2002).

\section{RESULTADOS E DISCUSSÃO}

As fontes de $\mathrm{N}$ aplicadas influenciaram a liberação de $\mathrm{N}-\mathrm{NO}_{3}{ }^{-}$e N-NH${ }_{4}{ }^{+}$em amostra de solo do Neossolo Quartzarênico. A liberação do $\mathrm{NH}_{4}{ }^{+}$e de $\mathrm{NO}_{3}{ }^{-}$no solo seguiu tendência linear com a aplicação das respectivas fontes de $\mathrm{N}$. Isto é, quanto mais $\mathrm{NH}_{4}{ }^{+}$aplicado no solo, maior o teor de $\mathrm{N}-\mathrm{NH}_{4}{ }^{+}$disponível às plantas $\mathrm{e}$ menor o teor de $\mathrm{N}-\mathrm{NO}_{3}^{-}$(Figura 1 ).

Observou-se que, no solo que recebeu a aplicação do tetracloreto de $\mathrm{Si}$, os teores das duas formas de $\mathrm{N}$ diminuiu (Figura 1). O teor $\mathrm{N}_{-} \mathrm{NO}_{3}{ }^{-}$no solo nãorizosférico foi de $19,1(+\mathrm{Si})$ e de $11,9 \mathrm{mg} \mathrm{kg}^{-1}$ quando

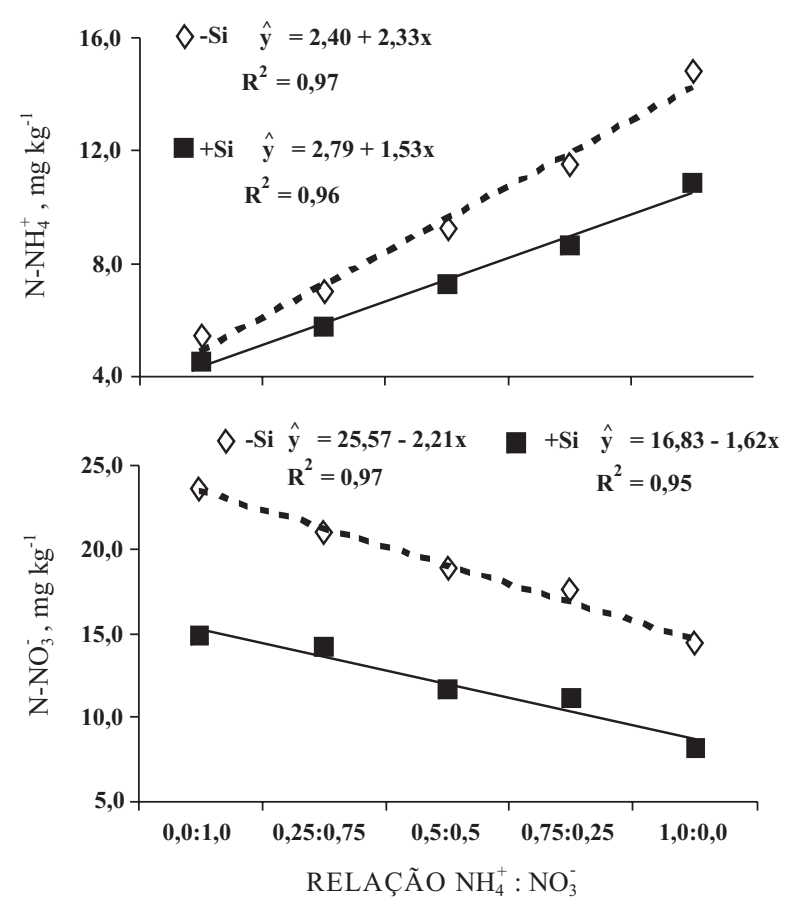

Figura 1. Teor de amônio $\mathrm{N}_{-} \mathrm{NH}_{4}^{+}$e de nitrato $\left[\mathrm{N}-\mathrm{NO}_{3}{ }^{-}\right]$no solo, em função de diferentes relações $\mathrm{N}-\mathrm{NH}_{4}^{+}: \mathrm{N}_{-} \mathrm{NO}_{3}^{-}$, na presença e ausência de silício no solo não-rizosférico do arroz. 
se aplicou a fonte silicatada (-Si); para o $\mathrm{NH}_{4}{ }^{+}$, essa diferença apresenta-se de forma mais discreta passando de 8,8 para $7,9 \mathrm{mg} \mathrm{kg}^{-1}$, com a aplicação de Si. Deve-se considerar o efeito do melhor crescimento vegetal pela aplicação de $\mathrm{Si}$, fazendo com que a planta de arroz absorvesse maior quantidade de $\mathrm{N}$, reduzindo seu teor no solo.

$\mathrm{O}$ aumento de $\mathrm{N}-\mathrm{NH}_{4}{ }^{+}$levou à diminuição do $\mathrm{pH}$; a acidificação dos solos rizosférico e não-rizosférico foi proporcional ao aumento do teor de amônio no solo (Figura 2).

A variação de $\mathrm{pH}$ obedeceu ao balanço de carga na rizosfera, isto é, enquanto a absorção de $\mathrm{N}_{-} \mathrm{NH}_{4}{ }^{+}$tende a acidificar, a de $\mathrm{N}_{-} \mathrm{NO}_{3}{ }_{3}$ tende a alcalinizar, tanto no solo rizosférico quanto no não-rizosférico.

$\mathrm{O}$ pH do solo rizosférico (Figura 2b) na cultura do arroz apresenta tendência de alcalinização em relação ao $\mathrm{pH}$ do solo não-rizosférico (Figura 2a). Essa alcalinização rizosférica deve-se, provavelmente, à maior produção de hidroxila, em virtude de a absorção de $\mathrm{NO}_{3}{ }^{-}$ser maior que a de $\mathrm{NH}_{4}{ }^{+}$. Essa alcalinização do solo rizosférico foi ligeiramente aumentada pela aplicação de $\mathrm{Si}$, passando de 5,9 sem adição de Si para 6,1 com a aplicação (Figura $2 b$ ). O efeito do Si no aumento de $\mathrm{pH}$ só foi observado no solo rizosférico, podendo esse aumento de $\mathrm{pH}$ estar mais relacionado com a própria dinâmica do sistema radicular do arroz do que com a aplicação de Si.

(a)

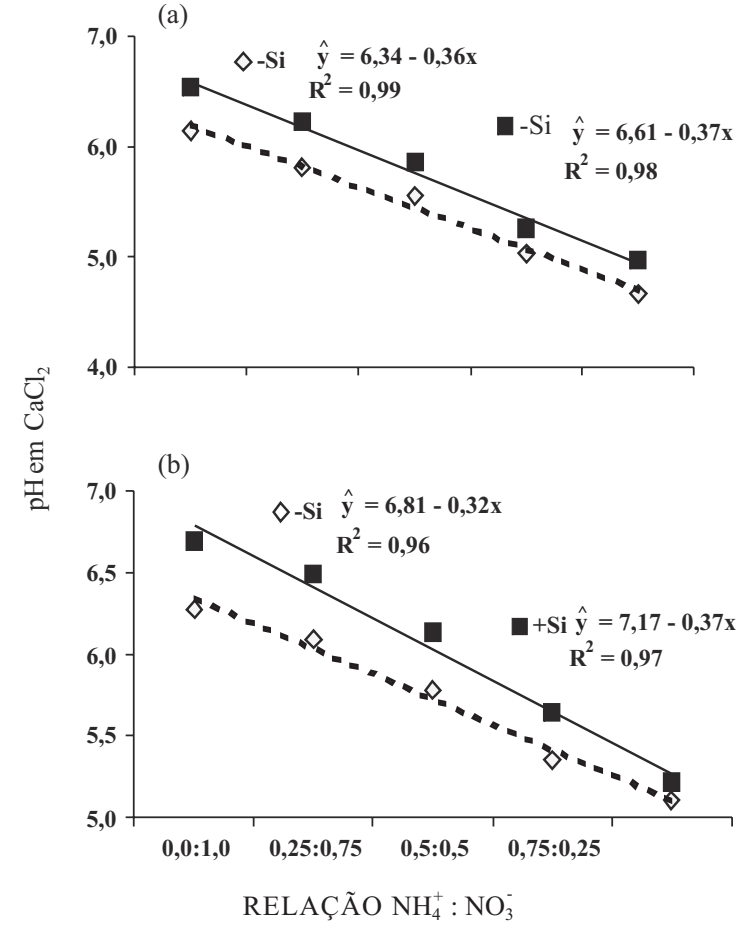

Figura 2. Valores de pH em $\mathrm{CaCl}_{2}$, em função de diferentes relações $\mathrm{N}-\mathrm{NH}_{4}{ }^{+}: \mathrm{NO}_{3}{ }^{-}$na presença e ausência de Si. (a) solo não-rizosférico; (b) solo rizosférico.
$\mathrm{O}$ aumento do $\mathrm{pH}$ rizosférico decorrente da aplicação de Si é de fundamental importância, pois o pH da rizosfera tem influência na solubilidade de nutrientes e na sua absorção pela raiz. $\mathrm{O}$ aumento de $\mathrm{pH}$ diminui a absorção de fosfatos, mas aumenta a absorção de alguns micronutriente como o Mn (Marschner \& Römheld, 1983), o que pode também estar acontecendo com o Si.

As amostras de solo utilizadas provêm de um Neossolo Quartzarênico com baixos teores de Si disponível na forma de ácido monossilícico, $1,3 \mathrm{mg} \mathrm{kg}^{-1}$ de Si (Quadro 1). A aplicação da fonte de Si (Titrisol, Merck $^{\circledR}$ ) na dose de $200 \mathrm{mg} \mathrm{kg}^{-1}$ apresentou-se pouco eficiente na liberação desse nutriente para o solo (Figura 3).

$\mathrm{O}$ aumento do teor de $\mathrm{NH}_{4}{ }^{+}$diminuiu o teor de Si disponível no solo (Figura 3), o que pode ser devido à formação de polímeros de $\mathrm{Si}$ com o $\mathrm{NH}_{4}{ }^{+}$. Observase que a aplicação de Si também diminuiu o teor de N no solo (Figura 1). Já que a forma de Si considerada foi de $\mathrm{H}_{4} \mathrm{SiO}_{4}$, não sendo detectados os polímeros deste elemento pelo método empregado (Iler, 1979).

O teor de Si disponível no solo correlaciona-se com a forma de $\mathrm{N}$ absorvida; quando a absorção de cátions pelas raízes das plantas excede a absorção de ânions, a solubilidade de Si é diminuída pelo aumento da acidificação do solo. Por outro lado, a absorção de ânions excede a absorção de cátions, a solubilidade do Si aumenta, devido à elevação do pH (Wallace, 1992).
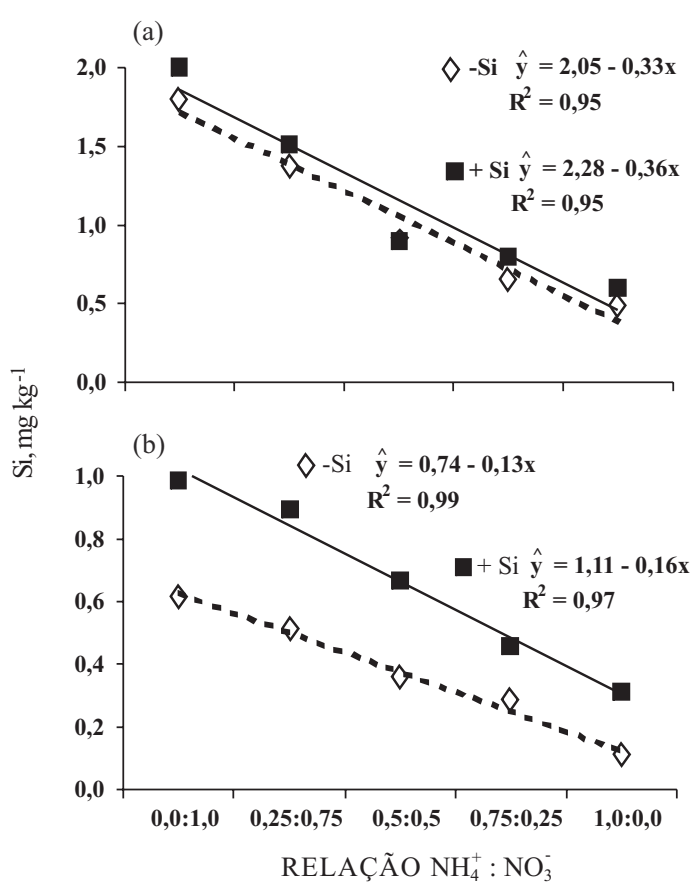

Figura 3. Teor de silício disponível no solo, extraído por $\mathrm{CaCl}_{2}$, em função de diferentes relações $\mathrm{N}$ $\mathrm{NH}_{4}^{+}: \mathrm{NO}_{3}^{-}$, na presença e ausência de Si no cultivo de arroz. (a) solo não-rizosférico; (b) solo rizosférico. 
Assim, a variação na disponibilidade de Si deve-se ao efeito indireto das formas de $\mathrm{N}$ na mudança de $\mathrm{pH}$ do meio.

$\mathrm{O} \mathrm{pH}$ em $\mathrm{CaCl}_{2}$ decresceu com o aumento do teor de $\mathrm{NH}_{4}{ }^{+}$no solo; para o Si no solo, a tendência foi a mesma do $\mathrm{pH}$. Assim, pode-se concluir que a disponibilidade de Si ocorre em função do $\mathrm{pH}$, ou seja, em $\mathrm{pH}$ mais alcalino, a concentração de $\mathrm{Si}$ foi aumentada no solo (Figura 4).

Em pH ácido, o monômero $\left(\mathrm{H}_{4} \mathrm{SiO}_{4}\right)$ polimeriza para formar precipitados de sílica amorfa (Iler, 1979), o que pode acarretar perda de Si solúvel. Isso ocorre principalmente quando o teor de Si é alto e o $\mathrm{pH}$ baixo. Outro fator que pode estar ocorrendo é a adsorção do Si por óxidos e hidróxidos de $\mathrm{Fe}$ e Al, que é mais intensa quanto mais baixo for o $\mathrm{pH}$ (Jackson, 1964).

O incremento no teor de Si na planta está relacionado de forma indireta com a concentração de $\mathrm{NO}_{3}{ }^{-}$, devido à alteração de $\mathrm{pH}$ criada por esse íon. Assim, a acumulação de Si na parte aérea foi proporcional ao aumento de $\mathrm{pH}$ do solo rizosférico em $\mathrm{CaCl}_{2}$ (Figura 5). $\mathrm{O} \mathrm{N}$ fornecido na forma amoniacal diminuiu em até $32 \%$ a absorção de Si em arroz, o que está de acordo com Ma \& Takahashi (2002) e Mauad et al. (2003), os quais observaram que a nutrição com $\mathrm{N}$ na forma de $\mathrm{NO}_{3}{ }^{\circ}$ diminuiu o teor de Si na planta de arroz de sequeiro.

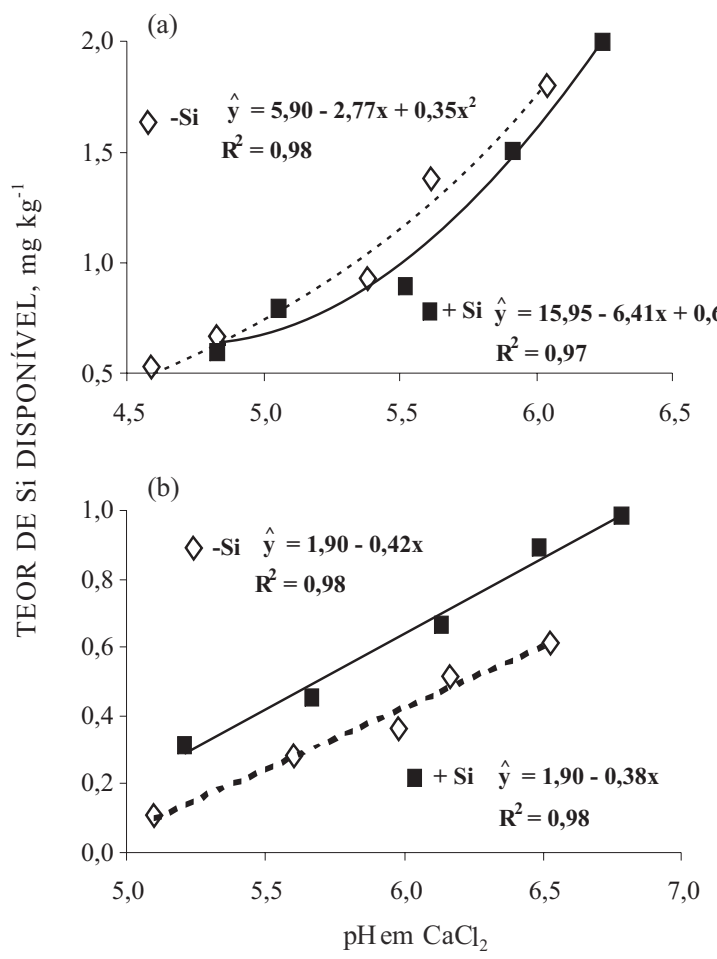

Figura 4. Teor de silício disponível no solo, extraído $\mathrm{em} \mathrm{CaCl}_{2}$,em função do $\mathrm{pH}$ do solo. (a) solo nãorizosférico; e (b) solo rizosférico.
O acúmulo de Si na planta de arroz foi menor no tratamento em que predominou o $\mathrm{NO}_{3}{ }^{-}$acompanhado pela taxa de clorofila (Figura 6), tendo essas variáveis relação positiva com a biomassa vegetal (Quadro 3). Isso ocorre porque os tratamentos com $\mathrm{NO}_{3}{ }^{-} \mathrm{e} \mathrm{NH}_{4}{ }^{+}$ equilibradas disponibilizaram mais $\mathrm{N}$, o que levou à maior produtividade (Quadro 3).

Em todas as relações entre as formas de $\mathrm{N}$, a aplicação de Si conferiu maior valor SPAD, quando comparado aos tratamentos que não receberam aplicação de Si. Os mesmos resultados foram observados por Deren et al. (1994) na cultura do morango, cuja aplicação de silicato de K, via foliar, fez com que a concentração de clorofila aumentasse de 40,2 para $64,2 \mu \mathrm{g} \mathrm{cm}^{-2}$ com a aplicação de silicato.

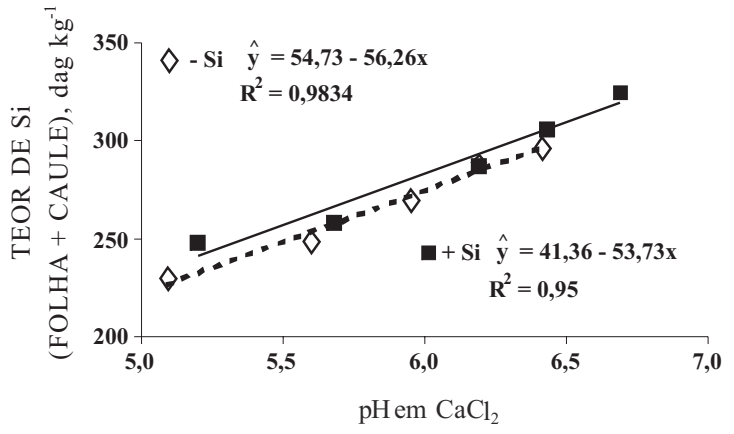

Figura 5. Teor de Si na parte aérea do arroz, em função do pH do solo rizosférico.
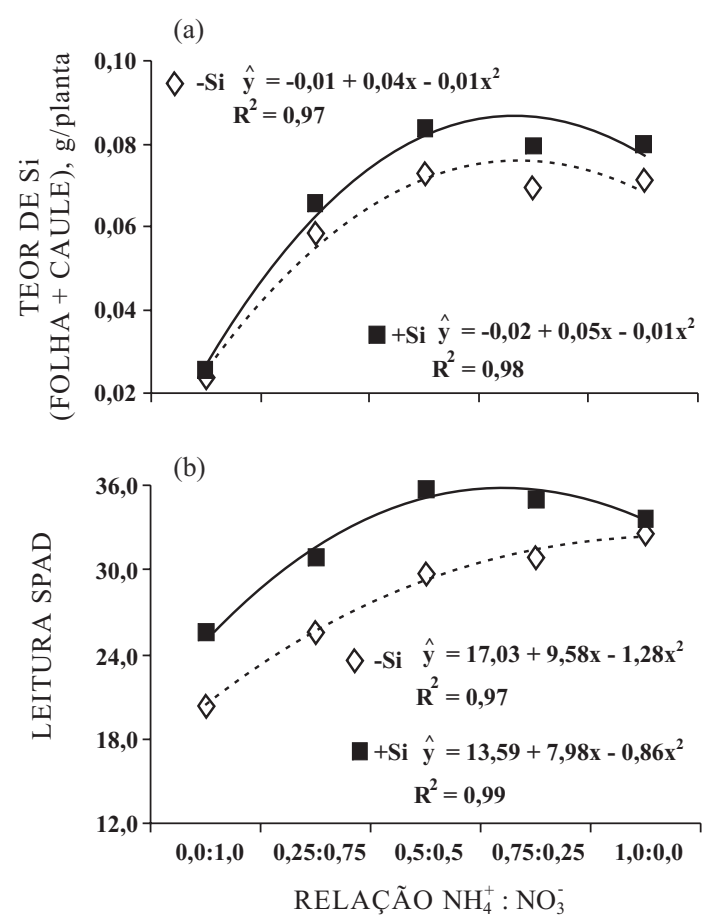

Figura 6. Acúmulo de Si na parte aérea (folha + caule) do arroz e leitura SPAD, em função de diferentes relações ${\mathrm{N}-\mathrm{NH}_{4}}^{+}: \mathrm{N}^{-\mathrm{NO}_{3}}{ }^{-}$. 
Quadro 3. Matéria seca da parte aérea (folha + caule) e raiz de arroz, cultivado em Neossolo Quartzarênico, com e sem aplicação de Si no solo

\begin{tabular}{|c|c|c|c|c|}
\hline \multirow{2}{*}{ Relações $\left(\mathrm{N}-\mathrm{NH}_{4}{ }^{+}\right.$e $\left.\mathrm{N}-\mathrm{NO}_{3}{ }^{-}\right)$} & \multicolumn{2}{|c|}{ Folha + caule } & \multicolumn{2}{|c|}{ Raiz } \\
\hline & $-\mathrm{Si}$ & $+\mathrm{Si}$ & $-\mathrm{Si}$ & $+\mathrm{Si}$ \\
\hline $0,0: 1,0$ & $0,8 \mathrm{cA}$ & $0,8 \mathrm{cA}$ & $0,3 \mathrm{bA}$ & $0,3 \mathrm{bA}$ \\
\hline $0,25: 0,75$ & $2,0 \mathrm{bA}$ & $2,0 \mathrm{bA}$ & $0,5 \mathrm{abA}$ & $0,6 \mathrm{aA}$ \\
\hline $0,50: 0,50$ & $2,8 \mathrm{aA}$ & $2,8 \mathrm{aA}$ & $0,6 \mathrm{aB}$ & $0,7 \mathrm{aA}$ \\
\hline $0,75: 0,25$ & $3,2 \mathrm{aA}$ & $3,3 \mathrm{aA}$ & $0,7 \mathrm{aA}$ & $0,7 \mathrm{aA}$ \\
\hline $0,1: 0,0$ & $2,9 \mathrm{aA}$ & $2,9 \mathrm{aA}$ & $0,6 \mathrm{aA}$ & $0,5 \mathrm{aA}$ \\
\hline Médias & $2,0 \mathrm{~A}$ & $2,1 \mathrm{~A}$ & $0,5 \mathrm{~A}$ & $0,3 \mathrm{~A}$ \\
\hline \multirow[t]{5}{*}{ Testemunha } & $1,4 \mathrm{bcA}$ & $1,4 \mathrm{bA}$ & $0,3 \mathrm{bB}$ & $0,5 \mathrm{aA}$ \\
\hline & \multicolumn{2}{|c|}{ DMS linha $=0,27$} & \multicolumn{2}{|c|}{ DMS linha $=0,09$} \\
\hline & \multicolumn{2}{|c|}{ DMS coluna $=0,62$} & \multicolumn{2}{|c|}{ DMS coluna $=0,21$} \\
\hline & \multicolumn{2}{|c|}{$\mathrm{CV}$ linha $=16,2 \%$} & \multicolumn{2}{|c|}{$\mathrm{CV}$ linha $=20,2 \%$} \\
\hline & \multicolumn{2}{|c|}{$\mathrm{CV}$ coluna $=3,5 \%$} & \multicolumn{2}{|c|}{$\mathrm{CV}$ coluna $=2,9 \%$} \\
\hline
\end{tabular}

Médias seguidas de letras distintas, minúsculas na coluna e maiúsculas na linha, diferem entre si pelo teste Tukey $(p<0,05)$.

\section{CONCLUSÕES}

1. $\mathrm{O}$ pH do solo rizosférico na cultura do arroz decresceu proporcionalmente ao aumento do teor de $\mathrm{N}-\mathrm{NH}_{4}{ }^{+}$, em relação ao $\mathrm{N}-\mathrm{NO}_{3}{ }^{-}$, e mostrou-se superior ao $\mathrm{pH}$ do solo.

2. A disponibilidade de Si no solo e sua absorção pela planta de arroz foram proporcionais às alterações ocorridas no $\mathrm{pH}$ da rizosfera. Quanto maior o $\mathrm{pH}$, maior a disponibilidade do Si no solo e maior seu teor na planta de arroz.

\section{LITERATURA CITADA}

ARGENTA, G.; SILVA, P.R.F.; MIELNICZUK, J. \& BORTOLINI, C.G. Parâmetros de planta como indicadores do nível de nitrogênio na cultura do milho. Pesq. Agropec. Bras., 37:519-517, 2002.

CHANCY, H.F. \& KAMPRATH. E.J. Effect of nitrapyrin on N response of corn an sandy soils. Agron. J., 74:565-569, 1982.

DEREN, C.W.; DATNOFF, L.E.; SNYDER, G.H. \& MARTIN, F.G. Silicon concentration, disease response, and yield components of rice genotypes grown on flooded organic Histosols. Crop Sci., 34:733-737, 1994.

EMPRESA BRASILEIRA DE PESQUISA AGROPECUÁRIA EMBRAPA. Serviço Nacional de Levantamento e Conservação de Solos. Manual de métodos de análises de solos. Rio de Janeiro, 1979. 212p.

GIJSMAN, A. Nitrogen nutrition and rhizosphere $\mathrm{pH}$ of Douglas-fir. Groningen, Rijksuniversiteit Groningen, 1990.132p. (Tese de Doutorado)
ILER, R.K. The chemistry of silica. New York, John Wiley \& Sons, 1979. 687p.

JACKSON, M.L. Chemical composition of soil. In: BEAR, F.E., ed. Chemistry of the soil. 2.ed. New York, Reinhold, 1964. p.71-141.

KORNDÖRFER, G.H.; ARANTES, V.A.; CORREA, G.F. \& SNYDER, G.H. Efeito da aplicação do silicato de cálcio no teor de silício e produção de grãos no arroz de sequeiro. R. Bras. Ci. Solo, 23:35-41, 1999.

KORNDÖRFER, G.H.; PEREIRA, H.S. \& CAMARGO, M.S Métodos para análise de silício no solo e na planta. Uberlândia, GPSi-ICIAG-UFU, 2004. 24p. (Boletim Técnico, 1)

MA, J. F. \& TAKAHASHI, E. Soil, fertilizer, and plant silicon research in Japan. Tokio, Elsevier, 2002. 274p.

MA, J.F.; MIYAKE, Y. \& TAKAHASHI, E. Silicon as a beneficial element for crop plant. In: DATNOFF, L.E.; SNYDER, G.H. \& KORNDÖRFER, G.H., eds. Silicon in agriculture. Amsterdam, Elsevier Science, 2001. p.17-39.

MARSCHNER, H. \& RÖMHELD, V. Induced $\mathrm{pH}$ changes at the soil-root interface. Zeit. für Pflanz., 111:241-251, 1983.

MAUAD, M.; GRASSI FILHO, H.; CRUSCIOL, C.A.C. \& CORREA, J.C. Teores de silício no solo e na planta de arroz de terras altas com diferentes doses de adubação silicatada e nitrogenada. R. Bras. Ci. Solo, 27:867-873, 2003.

VETTORI, L. Métodos de análise de solo. Rio de Janeiro, Equipe de Pedologia e Fertilidade do Solo, 1969. 24p. (Boletim Técnico, 7)

WALLACE, A. Participation of silicon in cation-anion balance as a possible mechanism for aluminum and iron tolerance gramineae. J. Plant Nutr., 115:1345-1351, 1992. 